\title{
Uncoupling between CBF and oxygen metabolism in a patient with chronic subdural haematoma: case report
}

Tatsuya Ishikawa, Shingo Kawamura, Hiromu Hadeishi, Akifumi Suzuki, Nobuyuki Yasui, Fumio Shishido, Kazuo Uemura

\begin{abstract}
The regional cerebral blood flow (rCBF) and oxygen metabolism of a patient with a chronic subdural haematoma were examined quantitatively, using positron emission tomography (PET). Before operation, the rCBF was decreased slightly throughout the brain, whereas the regional oxygen extraction fraction (rOEF) was increased throughout the brain, with values ranging from 0.36 to $0 \cdot 60$. One month after operation, the rCBF had recovered remarkably in almost all regions and rOEF had decreased to within the normal range.
\end{abstract}

Surgical Neurology,

Radiology and Nuclear

Medicine, $\star$ Research

Institute for Brain and

Blood Vessels-AKITA,

Akita, Japan

T Ishikawa

S Kawamura

H Hadeishi

A Suzuki

N Yasui

F Shishido*

K Uemura*

Correspondence to:

Dr Ishikawa, Department of Surgical Neurology

Research Institute for Brain and Blood Vessels-AKITA 6-10 Senshu-Kubota-Machi, Akita 010, Japan

Received 8 May 1990 and in revised form 7 January

1991.

Accepted 18 April 1991

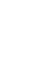

drinker. He had no previous head injury and was admitted to a local hospital complaining of both a gradual loss of activity during a two month period, and a weakness in his right hand and leg. The following day he had two grandmal seizure attacks. Ten days later, a large extra-axial mass lesion was detected by CT. He was then transferred to our hospital. When admitted he was disorientated and complained of frontal headache. Neurological examination revealed mild dementia and mild hemiparesis of the right side. The CT scan showed a massive subdural mass of mixed density, measuring $154 \mathrm{ml}$, with a shift of the mid-line structures (fig 1a). Regional cerebral blood flow (rCBF-ml/100 $\mathrm{ml} / \mathrm{min}$ ), cerebral blood volume (CBV-ml/100 $\mathrm{ml} / \mathrm{min}$ ), oxygen utiliza-
Figure 1 A) The CT scan on admission showed a massive subdural mass of mixed density, with a shift of mid-line structures; B) The CT scan, taken at six weeks after the operation, shows complete evacuation of the haematoma and resolution of the shifi of the midline structures. \begin{abstract}
tion $\left(\mathrm{CMRO}_{2}-\mathrm{ml} / 100 \mathrm{ml} / \mathrm{min}\right)$, and oxygen extraction fraction (OEF), were measured using a PET (HEADTOME III) and arterial blood sampling, during the sequential constant inhalation of $\mathrm{C}^{15} \mathrm{O}_{2}$ and ${ }^{15} \mathrm{O}_{2}$ and the single inhalation of $\mathrm{C}^{15} \mathrm{O}$.

The results in the regions of interest, were identified from the CT scan and are listed in the table. (Age-matched normal values for means (SD) measured by the HEADTOME III of our institute are as follows; CBF: $44 \cdot 2$ (7.3), CBV: $4.31(0.48), \mathrm{CMRO}_{2}: 3.04(0.44)$, OEF: $0.41(0.06)$, age: $56.7(5.6)$ years old.) The rCBF and $\mathrm{rCMRO}_{2}$ were decreased slightly throughout the brain. In the left frontotemporo-parietal cortex just under the haematoma, both rCBF and $\mathrm{rCMRO}_{2}$ had slightly higher values than in the corresponding region of the non-affected side. Only in the paraventricular deep white matter (corona radiata) were both $\mathrm{rCBF}$ and $\mathrm{rCMRO}_{2}$ lower in the affected side than in the non-affected side. The rCBV value was within the normal range, and there was not a focal increase in the region just under the haematoma. The rOEF throughout the brain was increased, with values over 0.45 in almost all the region. In the left cerebral hemisphere the OEF was slightly higher than on the right side(fig $2 a$ ).

Evacuation, irrigation, and drainage of the haematoma, through a single burr hole, were performed immediately after the PET study. The haematoma found was dark-red in colour and muddy. One week after the operation, the patient was alert and had no neurological deficit. The complete evacuation of the haematoma and recovery from the shift of the midline structures were verified by a CT scan (fig 1b).

It is unclear how a chronic subdural haemahemiparesis, aphasia, dementia, and impaired consciousness. Impairment of cerebral bloor emission tomography (PET) to measure the plood flow and oxygen metabolism a patient with a chronic subdural haemaCase report
\end{abstract}


Table Quantitative evaluation of ${ } \mathrm{CBF}, \mathrm{rCBV}$, rOEF, and ${ }^{\mathrm{CCMRO}}{ }_{2}$

\begin{tabular}{|c|c|c|c|c|c|c|c|c|c|}
\hline & \multicolumn{4}{|c|}{ right (non-affected side) } & \multicolumn{4}{|c|}{ left (affected side) } & \\
\hline & $r C B F$ & $r C B V$ & rOEF & $\mathrm{CCMRO}_{2}$ & $r C B F$ & $r C B V$ & $r O E F$ & $\mathrm{rCMRO}_{2}$ & \\
\hline $\begin{array}{l}\text { Before operation } \\
\text { Cerebellum } \\
\text { Frontal cortex } \\
\text { Temporal cortex } \\
\text { Head of caudate } \\
\text { Thalamus } \\
\text { Paraventricle } \\
\text { Parietal cortex } \\
\text { Occipital cortex }\end{array}$ & $\begin{array}{l}43 \cdot 6 \\
28 \cdot 5 \\
22 \cdot 5 \\
25 \cdot 3 \\
33 \cdot 9 \\
24 \cdot 4 \\
33 \cdot 1 \\
26 \cdot 4\end{array}$ & $\begin{array}{l}3 \cdot 37 \\
3 \cdot 43 \\
2 \cdot 80 \\
2 \cdot 80 \\
3 \cdot 21 \\
2 \cdot 76 \\
4 \cdot 54 \\
1.98\end{array}$ & $\begin{array}{l}0.53 \\
0.48 \\
0.36 \\
0.60 \\
0.49 \\
0.57 \\
0.52 \\
0.42\end{array}$ & $\begin{array}{l}3 \cdot 15 \\
1.91 \\
1 \cdot 23 \\
2 \cdot 04 \\
2 \cdot 26 \\
1.85 \\
2.34 \\
1.55\end{array}$ & $\begin{array}{l}46 \cdot 3 \\
31 \cdot 8 \\
32 \cdot 7 \\
31 \cdot 5 \\
36 \cdot 2 \\
19 \cdot 9 \\
36 \cdot 1 \\
43 \cdot 5\end{array}$ & $\begin{array}{l}3 \cdot 69 \\
2 \cdot 24 \\
3 \cdot 17 \\
3 \cdot 16 \\
6 \cdot 28 \\
2 \cdot 98 \\
2 \cdot 15 \\
9 \cdot 14\end{array}$ & $\begin{array}{l}0.50 \\
0.55 \\
0.57 \\
0.55 \\
0.46 \\
0.49 \\
0.47 \\
0.51\end{array}$ & $\begin{array}{l}3 \cdot 17 \\
2 \cdot 39 \\
2 \cdot 57 \\
2 \cdot 32 \\
2 \cdot 28 \\
1 \cdot 31 \\
2 \cdot 34 \\
3 \cdot 06\end{array}$ & $\begin{array}{l}\mathrm{Hb}: 10 \cdot 0 \\
\mathrm{PH}: 7 \cdot 484 \\
\mathrm{PaCO}_{2}: 34 \cdot 7 \\
\mathrm{PaO}_{2}: 91 \cdot 7\end{array}$ \\
\hline $\begin{array}{l}\text { After operation } \\
\text { Cerebellum } \\
\text { Frontal cortex } \\
\text { Temporal cortex } \\
\text { Head of caudate } \\
\text { Thalamus } \\
\text { Paraventricle } \\
\text { Parietal cortex } \\
\text { Occipital cortex }\end{array}$ & $\begin{array}{l}75 \cdot 5 \\
47 \cdot 3 \\
40 \cdot 0 \\
70 \cdot 0 \\
51 \cdot 4 \\
26 \cdot 8 \\
51 \cdot 8 \\
43 \cdot 3\end{array}$ & $\begin{array}{l}3.70 \\
3.94 \\
4.07 \\
3.91 \\
2.51 \\
1.28 \\
3.51 \\
4.05\end{array}$ & $\begin{array}{l}0.38 \\
0.34 \\
0.36 \\
0.34 \\
0.35 \\
0.42 \\
0.36 \\
0.36\end{array}$ & $\begin{array}{l}4 \cdot 50 \\
2 \cdot 06 \\
2 \cdot 32 \\
3 \cdot 70 \\
2 \cdot 76 \\
1 \cdot 74 \\
2 \cdot 92 \\
2 \cdot 40\end{array}$ & $\begin{array}{l}76 \cdot 3 \\
35 \cdot 3 \\
36 \cdot 8 \\
61 \cdot 5 \\
58 \cdot 7 \\
17 \cdot 2 \\
54 \cdot 5 \\
54 \cdot 7\end{array}$ & $\begin{array}{l}4.50 \\
3.13 \\
1.92 \\
4 \cdot 14 \\
4.96 \\
3.50 \\
3.55 \\
6.98\end{array}$ & $\begin{array}{l}0.35 \\
0.34 \\
0.39 \\
0.36 \\
0.33 \\
0.45 \\
0.32 \\
0.42\end{array}$ & $\begin{array}{l}4 \cdot 28 \\
1 \cdot 75 \\
2 \cdot 15 \\
3 \cdot 35 \\
3 \cdot 04 \\
1 \cdot 12 \\
2 \cdot 70 \\
3 \cdot 60\end{array}$ & $\begin{array}{l}\mathrm{Hb}: 11 \cdot 7 \\
\mathrm{PH}: 7 \cdot 422 \\
\mathrm{PaCO}_{2}: 34 \cdot 3 \\
\mathrm{PaO}_{2}: 85 \cdot 9\end{array}$ \\
\hline
\end{tabular}

${ }^{\star}$ Paraventricle deep white matter (corona radiata).

Cerebral angiography did not show either stenosis or occlusion of cerebral vessels. Six weeks after the operation, a PET study was repeated. The rCBF had increased to normal values in almost all regions. The relatively high level of $\mathrm{rCBF}$ and $\mathrm{CMRO}_{2}$ in the left frontotemporo-parietal cortex had fallen to normal. The $\mathrm{rCMRO}_{2}$ had also recovered, but was still below the normal range in some regions (for example, bilateral frontal cortex). The rOEF had decreased to within the normal range, measuring 0.32 to 0.45 in all regions (fig 2b).

\section{Discussion}

A few reports describe the cerebral blood flow and oxygen metabolism of patients with a chronic subdural haematoma. ${ }^{13-5} \mathrm{Kuhl}$ et a $\bar{P}$ examined the cerebral blood volume of headinjured patients, and reported that the CBV of patients with a subdural haematoma was increased in the cortex just under the haematoma, and returned to normal after surgical evacuation of the haematoma. They considered that the increase of CBV was due to the dilatation of the cortical vessels. They also believed that circulatory disturbance was responsible for the neurological deficits. However, only two of Kuhl's cases had a chronic subdural haematoma. Brodersen et $a l^{1}$ used the intra-arterial ${ }^{133} \mathrm{Xe}$ method to measure the hemispheric CBF of seven patients with chronic subdural haematoma before and after surgery and found that the hemispheric CBF on the affected side was below normal before the operation, but recovered after surgical evacuation of the haematoma. CBF and $\mathrm{CMRO}_{2}$ were measured in one patient whose $\mathrm{CMRO}_{2}$ was below normal, to $1.1 \mathrm{ml} / 100$ $\mathrm{g} / \mathrm{min}$, and was accompanied by a CBF thought to be caused by a reduced metabolic demand. Ikeda $e t a l^{4}$ used the ${ }^{133} \mathrm{Xe}$ inhalation method to measure rCBF. Each of their 21 cases had a bilateral decrease in the mean hemispheric $\mathrm{CBF}$ before operation with increases following surgery. In patients with a hemiparesis, rCBF at the Rolandic motor and
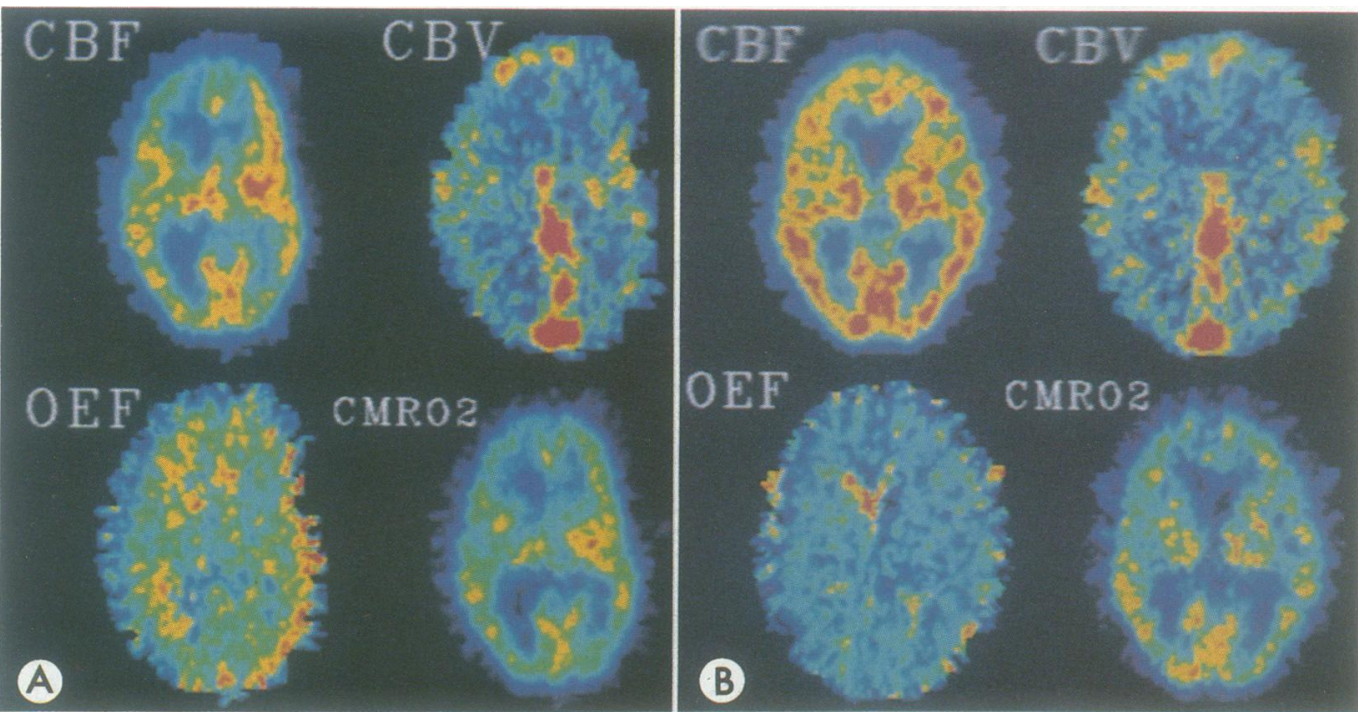

Figure 2 The regional blood flow ( $\mathrm{C} C B F$ ), the regional blood volume ( $\mathrm{CBBV}$ ), the regional axygen extraction fraction (rOEF), and the oxygen utilisation ( $\mathrm{r} C M R \mathrm{O}_{2}$ ) were measured in the preoperative $(A)$ and the postoperative period (B). (A): In the preoperative period, ,CBF and rCMRO slightly decreased throughout the brain. In the left fronto-temporo-parietal cortex just under the haematoma, both rCBF and rCMRO had slightly higher values than in the corresponding region of the right side. The rOEF increased throughout the entire brain. (B) Six weeks after the operation, the $r C B F$ and $r C M R O$ recovered in almost all regions. The rOEF decreased to within the normal range. 
sensory area were decreased significantly, but a focal decrease was not seen in patients with only a headache.

In our patient, a decrease in $\mathrm{rCBF}$ was found throughout the entire brain. We believe that this was the result of cerebral compression by the massive haematoma. The metabolic rate of oxygen was also moderately below normal and the rOEF value was high throughout the brain. This contrasts with the findings in cerebral ischaemia in which a haemodynamic reserve is initially produced by vascular dilatation. ${ }^{2}$ In our patient, vascular dilatation did not occur, oxygen transport reserve was called on, and consequently the OEF increased without an increase in CBV. Our findings also differ from those of Brodersen ${ }^{1}$ who found $\mathrm{CMRO}_{2}$ significantly decreased, along with a severe decrease of CBF, perhaps a reflection of the differences in the clinical severity of the two cases.

Ikeda $e t a l^{34}$ noted hypoperfusion in the Rolandic cortex of patients with a hemiparesis. In our case, however, even with the higher spatial resolution of PET we could not detect a low perfusion area corresponding with his hemiparesis and aphasia. Indeed, the CBF value in the affected hemisphere was higher than in the non-affected hemisphere. It is possible that this seemingly paradoxically low level of CBF could be caused by an increase of cerebral tissue volume in each pixel, as a consequence of compression of cortical sulci by the haematoma. On the other hand, the CBF was also depressed in the contralateral hemisphere. This general reduction of CBF is thought to be responsible for dementia and impairment of consciousness. A relatively preserved oxygen metabolism and a postoperative increase in CBF were related to the favourable response to surgery. However, in our patient, for reasons that are not clear, $\mathrm{rCMRO}_{2}$ did not return to the normal range in the bilateral frontal and temporal cortex.

Although our experience is based on only one patient, we believe that uncoupling of the $\mathrm{CBF}$ and oxygen metabolism throughout the brain occurred, and caused the neurological deficits.

1 Brodersen P, Gjerris F. Regional blood flow in patients with chronic subdural hematomas. Acta Neurol Skandinav 1975;51:233-9.

2 Frackowiak RS. Pathophysiology of human cerebral ischemia: Studies with positron tomography and ${ }^{15}$ oxygen. In: Sokoloff $\mathrm{L}$, ed. Brain imaging and brain function. New York: Raven Press, 1985:139-61.

3 Ikeda K, Kano A, Hayase H, Yamashita T, Itoh H, Yamamoto S. Relationship between symptoms of chronic subdural hematoma and hematoma volume or regional blood flow. Neurol Med Chir (Tokyo) 1984;24:869-75.

4 Ikeda K, Itoh H, Yamashima T, Saito K, Yamamoto S, Ishiguro S, Matsuda H: Symptoms and regional cerebral Ishiguro S, Matsuda H: Symptoms and regional cerebral
blood flow in chronic subdural hematoma. Neurol Med Chir (Tokyo) 1986;26:792-800.
Chood

5 Kuhl DE, Alavi A, Hoffman EJ, et al. Local cerebral blood volume in head-injured patients. Determination by emission computed tomography of ${ }^{99 \mathrm{~m}}$ Tc-labeled red cells. $\mathcal{f}$ Neurosurg 1980;52:309-20. 